\title{
Antimony as a symmetrically bridged ligand in a novel neutral complex
}

\author{
Manfred Scheer, ${ }^{* a}$ Jan Müller, ${ }^{a}$ G. Baum ${ }^{a}$ and Marco Häser ${ }^{b}$ \\ a Institute of Inorganic Chemistry, University of Karlsruhe, D-76128 Karlsruhe, Germany. \\ E-mail: mascheer@achibm6.chemie.uni-karlsruhe.de \\ ${ }^{b}$ Institute of Physical Chemistry, University of Karlsruhe, D-76128 Karlsruhe, Germany
}

\section{Received (in Basel, Switzerland) 20th August 1998, Accepted 13th October 1998}

$[\mathrm{LW}=\mathrm{Sb}=\mathrm{WL}] 7\left(\mathrm{~L}=\mathrm{N}\left(\mathrm{CH}_{2} \mathrm{CH}_{2} \mathrm{~N}(\mathrm{~Np})\right)_{3} ; \mathrm{Np}=\mathrm{CH}_{2} \mathrm{CMe}_{3}\right)$ is prepared by treatment of [ $\mathrm{LWCl}] 5$ with $\mathrm{LiSb}\left(\mathrm{SiMe}_{3}\right)_{2}-$ (dme $)_{n}$; the ethylene complex $\left[\mathrm{LWCl}\left(\mathrm{C}_{2} \mathrm{H}_{4}\right)\right] 6$ is a side product in the synthesis of 5; all complexes are structurally characterised.

Complexes of the general formula $\left[\mathrm{L}_{\mathrm{n}} \mathrm{M} \equiv \mathrm{E}\right](\mathrm{E}=\mathrm{P}$, As $)$ with terminal ligands represent a new class of compounds. ${ }^{1}$ With the synthesis and structural characterisation of the phosphido complexes $\left[\left(\mathrm{Ar}^{\prime} \mathrm{RN}\right)_{3} \mathrm{Mo} \equiv \mathrm{P}\right]\left(\mathrm{Ar}^{\prime}=3,5-\mathrm{C}_{6} \mathrm{H}_{3} \mathrm{Me}_{2}, \mathrm{R}=\right.$ $\left.\mathrm{C}\left(\mathrm{CD}_{3}\right)_{2} \mathrm{CH}_{3}\right) \mathbf{1}^{2}$ and $\left[\mathrm{N}\left(\mathrm{CH}_{2} \mathrm{CH}_{2} \mathrm{NSiMe}_{3}\right)_{3} \mathrm{M} \equiv \mathrm{E}\right][\mathrm{M}=\mathrm{W}$ (2a), Mo (2b) ${ }^{3}$ the speculation about the existence of stable compounds of this class was brought to an end. We have shown that one possibility to synthesise the phosphido complex 2a is starting from $\mathrm{Li}\left[\mathrm{P}\left(\mathrm{SiMe}_{3}\right)_{2}\right]$ according to eqn. (1). ${ }^{4}$ Using
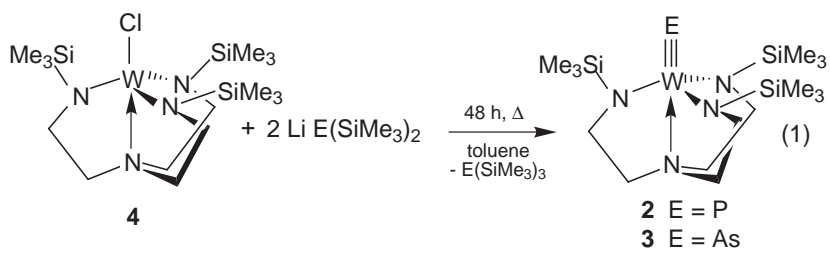

$\mathrm{Li}\left[\mathrm{As}\left(\mathrm{SiMe}_{3}\right)_{2}\right]$ in reaction (1), we were also able to synthesise and structurally characterise the arsenido derivative $3 .^{4}$ This raised the possibility of generating complexes with terminal antimonido and bismuthido ligands. The salts $\mathrm{Li}\left[\mathrm{E}\left(\mathrm{SiMe}_{3}\right)_{2}\right](\mathrm{E}$ $=\mathrm{P}, \mathrm{As}, \mathrm{Sb}, \mathrm{Bi}$ ) have been known for a long time for all pnictogen elements, ${ }^{5}$ therefore this seems to be a viable route to compounds containing terminal $\mathrm{Sb}$ and $\mathrm{Bi}$ ligands.

We have found, however, that irrespective of reaction conditions, the conversion between $\left[\left\{\mathrm{N}\left(\mathrm{CH}_{2} \mathrm{CH}_{2} \mathrm{NSi}-\right.\right.\right.$ $\left.\left.\left.\mathrm{Me}_{3}\right)_{3}\right\} \mathrm{WCl}\right] 4$ and $\mathrm{Li}\left[\mathrm{Sb}\left(\mathrm{SiMe}_{3}\right)_{2}(\mathrm{dme})_{n}\right]$ did not proceed. The steric demand of the $\mathrm{SiMe}_{3}$ groups in complex 4 obviously inhibits the substitution of the $\mathrm{Cl}$ atom by the Sb moiety. The use of a sterically less bulky tris(2-amidoethyl)amine ligand should however enable $\mathrm{W}-\mathrm{Sb}$ bond formation. Herein we report the synthesis and characterisation of $\left[\left\{\mathrm{N}\left(\mathrm{CH}_{2} \mathrm{CH}_{2} \mathrm{~N}(\mathrm{~Np})\right)_{3}\right\} \mathrm{WCl}\right] \mathbf{5}\left(\mathrm{Np}=\mathrm{CH}_{2} \mathrm{C}\left(\mathrm{CH}_{3}\right)_{3}\right)$ and the reactivity of 5 with $\mathrm{Li}\left[\mathrm{Sb}\left(\mathrm{SiMe}_{3}\right)_{2}(\mathrm{dme})_{n}\right]$.

The reaction of $\mathrm{WCl}_{4}(\mathrm{dme})$ with $\mathrm{Li}_{3}\left[\mathrm{~N}\left(\mathrm{CH}_{2} \mathrm{CH}_{2} \mathrm{~N}(\mathrm{~Np})\right)_{3}\right]$ leads to the brown compound $\left[\left\{\mathrm{N}\left(\mathrm{CH}_{2} \mathrm{CH}_{2} \mathrm{~N}(\mathrm{~Np})\right)_{3}\right\} \mathrm{WCl}\right] \mathbf{5}$. A small quantity of the green ethylene complex $\left[\left\{\mathrm{N}\left(\mathrm{CH}_{2} \mathrm{CH}_{2} \mathrm{~N}(\mathrm{~Np})\right)_{2} \mathrm{CH}_{2} \mathrm{CH}_{2} \mathrm{NH}(\mathrm{Np})\right\} \mathrm{WCl}\left(\eta^{2}-\mathrm{C}_{2} \mathrm{H}_{4}\right)\right] \mathbf{6}$ was also isolated. ${ }^{6}$ While complex 5 dissolves well in toluene and is moderately soluble in pentane, compound $\mathbf{6}$ undergoes decomposition even in solvents of low polarity, resulting in the formation of an insoluble solid which could not be characterised. In the mass spectra of $\mathbf{5}$ and $\mathbf{6}$ the peaks for the molecular ions are observed. The ${ }^{1} \mathrm{H}$ NMR spectrum of 5 reveals broad signals at high and low field for the paramagnetic $\mathrm{d}^{2}$-tungsten complex. $\dagger$

The source of the ethylene in $\mathbf{6}$ is uncertain. It is possibly a result of a fragmentation of the tren ligand itself. Schrock and co-workers observed $\mathrm{C}-\mathrm{N}$ bond cleavage of the ligand framework of a tren complex of tantalum, yielding a $\mathrm{N}$-allyl unit. ${ }^{7}$ Moreover, the low yields generally observed in the reactions of
chlorotungsten(IV) complexes with tren ligands indicate various side reactions during the synthesis. ${ }^{8}$

In the structure of the trigonal bipyramidal tungsten complex 5 the $\mathrm{W}-\mathrm{Cl}$ and the $\mathrm{W}-\mathrm{N}_{\mathrm{ax}}$ distances [2.389(2) and 2.179(5) $\left.\mathrm{A}\right]$ are only slightly shorter than the equivalent distances $[2.399(2)$ and 2.182(6) $\AA$ ] in the isostructural $\mathrm{Me}_{3} \mathrm{Si}$ substituted complex 4. In 6 (Fig. 1) the $\mathrm{W}$ atom exhibits a distorted octahedral coordination geometry. $\$$ This is one of the few examples where the tetradentate ligand tris(2-amidoethyl)amine does not bind in $\mathrm{C}_{3}$-symmetrical fashion to a transition metal. ${ }^{9}$ This is due to the formation of only two W-N bonds [W-N3 1.964(3), W-N4 $2.002(3) \AA]$, whereas $\mathrm{N}(2)$ and $\mathrm{N}(1)$ coordinate merely with their lone-pair to the tungsten centre [W-N1 2.254(3), W-N2 2.399(3) A]. The ethylene experiences strong back donation from the $\mathrm{d}^{2} \mathrm{~W}$ atom, which is evident from the elongated $\mathrm{C}-\mathrm{C}$ bond [1.416(6) $\AA$ ] and short W-C distances of 2.170(4) and $2.175(3) \AA$. The complex $\left[\mathrm{W}_{2}(\mathrm{ONp})_{6}\left(\eta^{2}-\mathrm{C}_{2} \mathrm{H}_{4}\right)_{2}\right]$, in which a bridging ethylene ligand forms a $\mathrm{W}_{2} \mathrm{C}_{2}$ tetrahedron with the $\mathrm{W}$ atoms, shows comparable bond lengths [W-C 2.14(2), C-C $1.45(2) \AA] .{ }^{10}$

The reaction of 5 with $\left[\mathrm{LiSb}\left(\mathrm{SiMe}_{3}\right)_{2}(\mathrm{dme})_{n}\right]$ for $48 \mathrm{~h}$ at 110 ${ }^{\circ} \mathrm{C}$ in the dark leads to $\mathrm{Sb}-\mathrm{W}$ bond formation as shown in eqn. (2). Instead of a terminal antimonido complex, the symmetrically Sb-bridged complex 7 is formed, which is the first neutral Sb-containing example for this class of compounds. Cationic complexes with $\mu-\mathrm{E}_{1}$ ligands for the heavy group 15 elements were described by Huttner and co-workers. ${ }^{11}$ Numerous compounds of the form $\left[\mathrm{L}_{n} \mathrm{M}=\mathrm{E}=\mathrm{ML}_{n}\right]$ are known, which contain a symmetrical nitrogen bridge, but not for pnictogens heavier than phosphorus. ${ }^{12}$ Stephan and co-workers succeeded in the synthesis of the complex $\left[\left\{\mathrm{Cp}_{2} \mathrm{Zr}\right\}_{2}(\mu-\mathrm{P})\right] \cdot{ }^{13}$ Cummins and co-workers isolated $\left[\left\{\left(\mathrm{R}^{\prime} \mathrm{RN}\right)_{3} \mathrm{Mo}\right\}_{2}(\mu-\mathrm{P})\right]\left(\mathrm{R}=\mathrm{Ph} ; \mathrm{R}^{\prime}=\right.$ $t$-Bu) at $-35^{\circ} \mathrm{C}$ as a labile intermediate in the transfer reaction of a terminal $\mathrm{P}_{1}$ ligand from the phosphido complex 1 to the $\mathrm{d}^{3}$ complex $\left[\left(\mathrm{R}^{\prime} \mathrm{RN}\right)_{3} \mathrm{Mo}\right]\left(\mathrm{R}^{\prime}=\mathrm{C}_{6} \mathrm{H}_{5}, \mathrm{R}=t\right.$-Bu $) .{ }^{14}$ It could not be established whether 7 is the result of such an irreversible

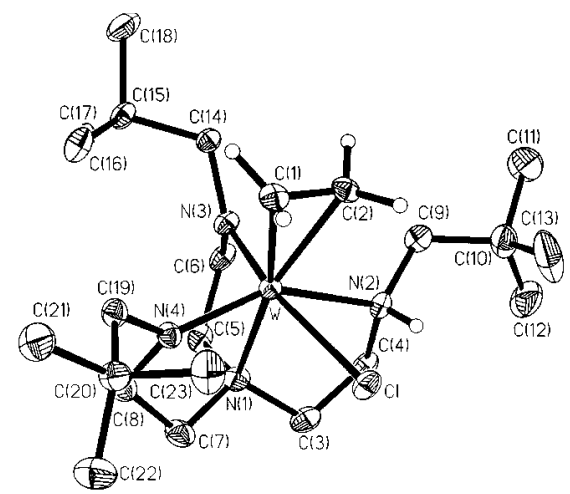

Fig. 1 Molecular structure of 6 (ellipsoids drawn at 30\% probability level). Selected bond lengths $[\AA]$ and angles $\left[{ }^{\circ}\right]$ : W-Cl $2.5116(12), \mathrm{W}-\mathrm{N}(1)$ 2.254(3), W-N(2) 2.399(3), W-N(3) 1.964(3), W-N(4) 2.002(3), C(1)$\mathrm{C}(2) 1.416(6), \mathrm{W}-\mathrm{C}(1) 2.175(3), \mathrm{W}-\mathrm{C}(2)$ 2.1704(4), C(1)-W-C(2) 38.0(2), $\mathrm{N}(1)-\mathrm{W}-\mathrm{Cl}$ 94.00(9), N(1)-W-C(1) 165.64(14), N(1)-W-C(2) 156.8 (13), $\mathrm{N}(1)-\mathrm{W}-\mathrm{N}(2) \quad 74.28(11), \quad \mathrm{N}(1)-\mathrm{W}-\mathrm{N}(3) \quad 79.69(12), \quad \mathrm{N}(1)-\mathrm{W}-\mathrm{N}(4)$ 80.41(12), Cl-W-N(2) 74.57(8), Cl-W-N(4) 92.26(10), N(2)-W-N(3) 87.71(12), N(3)-W-N(4) 102.90(14). 


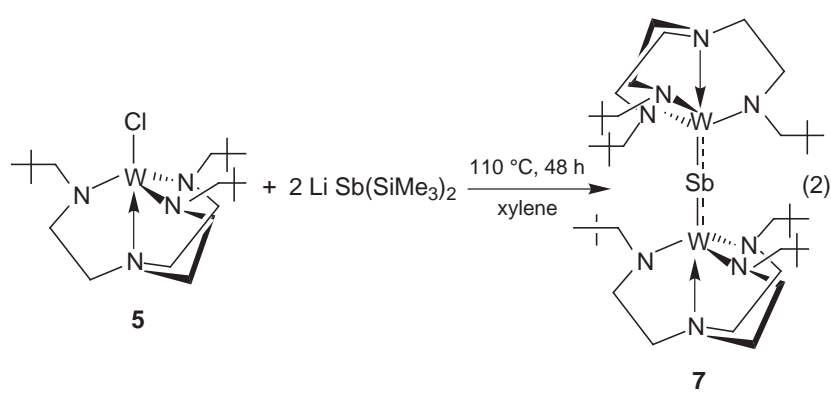

transfer reaction, or after an $\mathrm{Sb}-\mathrm{W}$ bond formation an intermolecular $\mathrm{Me}_{3} \mathrm{SiCl}$ elimination is followed. The $\mathrm{M}-\mathrm{E}-\mathrm{M}$ system of such neutral complexes possesses a $\left(1 \pi_{\mathrm{u}}\right)^{4}\left(1 \pi_{\mathrm{g}}\right)^{3}$ electron configuration with one unpaired electron. Therefore 7 is a mixed valent $\mathrm{W}(\mathrm{Iv}) / \mathrm{W}(\mathrm{v})$ species.

The molecular structure of 7 (Fig. 2) reveals two W-tren units bonded to one $\mathrm{Sb}$ atom in a staggered configuration. $\$$ To the best of our knowledge the Sb-W distance of 2.5738(8) $\AA$ is the shortest $\mathrm{Sb}-\mathrm{W}$ bond distance known. The $\mathrm{W}-\mathrm{N}_{\mathrm{eq}}$ bond lengths are consistent with those found in $\mathbf{2}$ and $\mathbf{3}$. The axial $\mathrm{W}-\mathrm{N}(1)$ bond in 7 is $0.1 \AA$ shorter than the equivalent distance in compounds containing a $\mathrm{W} \equiv \mathrm{E}$ triple bond $\left(\mathrm{E}=\mathrm{P},{ }^{3} \mathrm{As}^{4}\right)$.

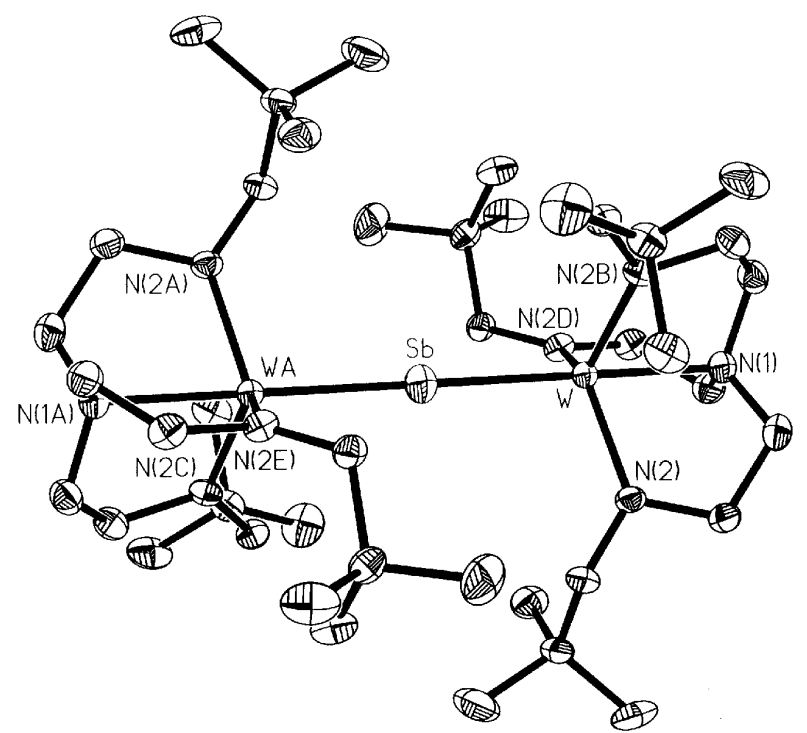

Fig. 2 Molecular structure of 7 (ellipsoids drawn at 30\% probability level). Selected bond lengths $[\AA]$ and angles $\left[^{\circ}\right]$ : W-Sb 2.5738(8), W-N(1) $2.243(14), \mathrm{W}-\mathrm{N}(2) 2.000(7), \mathrm{W}-\mathrm{Sb}-\mathrm{W}$ 180.0, Sb-W-N(1) 180.0, Sb-W$\mathrm{N}(2)$ 101.0(2), N(1)-W-N(2) 79.0(2), N(2)-W-N(2) 116.4(1).

The equilibrium structure of 7 was calculated using the BP86/SVP approximation. ${ }^{15}$ The equal W-Sb bond distances of the paramagnetic compound 7 with respect to an almost linear $\mathrm{W}-\mathrm{Sb}-\mathrm{W}$ framework of $179.6^{\circ}$ are $2.612 \AA$. The experimental distance of the exact linear system in 7 with a centre of inversion at the $\mathrm{Sb}$ atom is found to be approximately $0.04 \AA$ shorter. According to the calculations, the corresponding Np-substituted complex with a terminal antimonido ligand possesses a $\mathrm{W}-\mathrm{Sb}$ bond length of $2.514 \AA$, an anionic form of complex 7 reveals a $\mathrm{W}-\mathrm{Sb}$ distance of $2.609 \AA$

The results show that a reduction of the steric demand of the $\mathrm{R}$ group on the tren ligand leads to novel neutral Sb-bridged complexes. Current work is directed towards the synthesis of such complexes of the other pnictides and towards an optimisation of the size of the substituent $\mathrm{R}$ on the tren ligand in order to generate complexes with terminal $\mathrm{Sb}$ and $\mathrm{Bi}$ ligands.

The authors thank the Deutsche Forschungsgemeinschaft and the Fonds der Chemischen Industrie for financial support.

\section{Notes and references}

$\dagger$ Spectroscopic data: 5: ${ }^{1} \mathrm{H}$ NMR $\left(\mathrm{C}_{6} \mathrm{D}_{6}\right) \delta 9.36\left(\mathrm{~s}, \mathrm{CH}_{3}\right),-26.1\left(\mathrm{~b}, \mathrm{CH}_{2}\right)$, $-56.4\left(\mathrm{~b}, \mathrm{CH}_{2}\right)$; FI-MS $\left(70 \mathrm{eV}, 120^{\circ} \mathrm{C}\right) \mathrm{m} / \mathrm{z}(\%): 573(100)\left[\mathrm{M}^{+}\right]$; 6: FI-MS $\left(10 \mathrm{kV}, 120{ }^{\circ} \mathrm{C}\right) \mathrm{m} / \mathrm{z}(\%): 603(100)\left[\mathrm{M}^{+}\right], \mathrm{C}, \mathrm{H}, \mathrm{N}, \mathrm{Calc}$. for $\mathrm{C}_{23} \mathrm{H}_{50} \mathrm{ClN}_{4} \mathrm{~W}$ : C 45.89; $\mathrm{H}$ 8.37; N 9.31; found: C 45.69; H 8.38; N 9.13; 7: $\mu_{\text {eff }}$ (Evan's method, $\left.\mathrm{C}_{6} \mathrm{D}_{8}, 300 \mathrm{~K}\right)=2.07 \mu_{\mathrm{B}}$; EI-MS $\left(70 \mathrm{eV}, 180{ }^{\circ} \mathrm{C}\right): 1197(8)\left[\mathrm{M}^{+}\right]$, 660 (91) $\left[\mathrm{WSbN}_{4} \mathrm{C}_{21} \mathrm{H}_{45}{ }^{+}\right], 603$ (100) $\left[\mathrm{WSbN}_{4} \mathrm{C}_{18} \mathrm{H}_{39}{ }^{+}\right]$.

\$ Crystal structure analyses of 5-7 were performed on a STOE STADI IV $(\omega$-scan mode) diffractometer with Mo-K $\alpha$ radiation $(\lambda=0.71073 \AA)$ with empirical absorption corrections (Psi-scans). The structures were solved by direct methods using SHELXS-86, ${ }^{16} a$ full-matrix-least-squares refinement on $F^{2}$ in SHELXL-9316b with anisotropic displacement for non-H atoms. Hydrogen atoms were located in idealized positions and refined isotropically according to the riding model. Crystal structure analysis: 5: $\mathrm{C}_{21} \mathrm{H}_{45} \mathrm{ClN}_{4} \mathrm{~W}, M=572.91$, monoclinic, space group $P 2{ }_{1} / c ; a=$ 13.203(3), $b=11.450(2), c=17.000(3) \AA, \beta=91.74(3)^{\circ}, T=200(2) \mathrm{K}$, $Z=4, U=2568.8(9) \AA^{3}, D_{\mathrm{c}}=1.481 \mathrm{Mg} \mathrm{m}^{-3}, \mu(\mathrm{Mo}-\mathrm{K} \alpha)=46.13 \mathrm{~cm}^{-1}$, $F(000)=1160$. A total of 5441 reflections with $3.08 \leqslant 2 \theta \leqslant 55.02^{\circ}$ were collected, of which 5404 were independent and 4048 reflections with $I \geqslant$ $2 \sigma(I)$. Final residuals are $R_{1}=0.0370$ and $w R_{2}=0.1024$ and GOF $=1.129$ for 253 variables. Residual electron density was found to be between 1.072 and $-0.728 \mathrm{e} \AA^{-3}$. 6: $\mathrm{C}_{23} \mathrm{H}_{50} \mathrm{ClN}_{4} \mathrm{~W}, M=601.97$, monoclinic, space group $P 2{ }_{1} / n ; a=11.185(2), b=17.142(3), c=14.216(3) \AA, \beta=95.13(3)^{\circ}, T$ $=203(2) \mathrm{K}, Z=4, U=2714.8(9) \AA^{3}, D_{c}=1.473 \mathrm{Mg} \mathrm{m}^{-3}, \mu(\mathrm{Mo}-\mathrm{K} \alpha)$ $=43.69 \mathrm{~cm}^{-1}, F(000)=1228$. A total of 4171 reflections with $3.74 \leqslant 2 \theta$ $\leqslant 50.04^{\circ}$ were collected, of which 4171 were independent and 3835 reflections with $I \geqslant 2 \sigma(I)$. Final residuals are $R_{1}=0.0240$ and $w R_{2}=$ 0.0665 and $\mathrm{GOF}=1.045$ for 271 variables. Residual electron density was found to be between 1.735 and -1.880 e $\AA^{-3}$. 7: $\mathrm{C}_{42} \mathrm{H}_{90} \mathrm{~N}_{8} \mathrm{SbW}_{2}, M=$ 1196.67, trigonal, space group $R \overline{3}$; (no. 148), $a=b=16.409(3), c=$ $15.669(3) \AA, T=200(2) \mathrm{K}, Z=3, U=3653.7(12) \AA^{3}, D_{\mathrm{c}}=1.632 \mathrm{Mg}$ $\mathrm{m}^{-3}, \mu(\mathrm{Mo}-\mathrm{K} \alpha)=52.97 \mathrm{~cm}^{-1}, F(000)=1791$. A total of 1840 reflections with $3.86 \leqslant 2 \theta \leqslant 54.96^{\circ}$ were collected, of which 1840 were independent and 1555 reflections with $I \geqslant 2 \sigma(I)$. Final residuals of $R_{1}=0.0470$ and $w R_{2}$ $=0.1288$ and $\mathrm{GOF}=1.112$ for 83 variables. Residual electron density was found to be between 1.634 and -2.153 e $\AA^{-3}$. CCDC 182/1058.

1 Reviews: M. Scheer, Angew. Chem., 1995, 107, 2151; Angew. Chem., Int. Ed. Engl., 1995, 34, 1997; Coord. Chem. Rev., 1997, 163, 271.

2 C. E. Laplaza, W. M. Davis and C. C. Cummins, Angew. Chem., 1995, 107, 2181; Angew. Chem., Int. Ed. Engl., 1995, 34, 2042

3 N. Zanetti, R. R. Schrock and W. M. Davis, Angew. Chem., 1995, 107, 2184; Angew. Chem., Int Ed. Engl., 1995, 34, 2044.

4 M. Scheer, J. Müller and M. Häser, Angew. Chem., 1996, 108, 2637; Angew. Chem., Int. Ed. Engl., 1996, 35, 2492.

5 G. Becker, A. Münch and C. Witthauer, Z. Anorg. Allg. Chem., 1982, 492, 15; G. Becker and C. Witthauer, Z. Anorg. Allg. Chem., 1982, 492, 28; O. Mundt, G. Becker, M. Rössler and C. Witthauer, Z. Anorg. Allg. Chem., 1983, 506, 42.

$6 \mathrm{Li}_{3}\left[\mathrm{~N}\left(\mathrm{CH}_{2} \mathrm{CH}_{2} \mathrm{NNp}\right)_{3}\right]$ was synthesised from $\mathrm{N}\left(\mathrm{CH}_{2} \mathrm{CH}_{2} \mathrm{NNp}\right)_{3}$ with three equivalents of BuLi. The neopentyl-substituted amine is obtained from conversion of tris(2-amionoethyl)amine with pivalinic anhydride and subsequent reaction of the acid amide with $\mathrm{LiAlH}_{4}$. The complex 5 was synthesised according to a modified procedure ${ }^{4} \mathbf{6}$ crystallises in the form of green crystals along with $\mathbf{5}$.

7 J. S. Freundlich, R. R. Schrock and W. M. Davis, J. Am. Chem. Soc., 1996, 118, 3643.

8 Usually the yields are below $15 \%$. Using fluorinated substituents, however, more of the designed product can be obtained.

9 Compare: D. A. Dobbs, R. R. Schrock and W. M. Davis, Inorg. Chim. Acta, 1997, 263, 171.

10 S. T. Chacon, M. H. Chisholm, O. Eisenstein and J. C. Huffmann, J. Am. Chem. Soc., 1992, 114, 8497.

11 A. Strube, G. Huttner and L. Zsolnai, Angew. Chem., 1988, 100, 1586; F. Bringewski, G. Huttner and W. Imhof, J. Organomet. Chem., 1993, 448, C3; S. J. Davies, N. A. Compton, G. Huttner, L. Zsolnai and S. E. Garner, Chem. Ber., 1991, 124, 2731.

12 K. Dehnicke and J. Strähle, Angew. Chem., 1992, 104, 978; Angew. Chem., Int. Ed. Engl., 1992, 32, 955.

13 M. C. Fermin, J. Ho and D. W. Stephan, Organometallics, 1995, 14, 4247.

14 M. J. A. Johnson, P. M. Lee, A. L. Odom, W. M. Davis and C. C. Cummins, Angew. Chem., 1997, 109, 110; Angew. Chem., Int. Ed. Engl., 1997, 36, 87.

15 Structure optimizations were performed using the TURBOMOLE set of programs with the RI-J approximation (K. Eichhorn, O. Treutler, H. Öhm, M. Häser and R. Ahlrichs, Chem. Phys. Lett., 1995, 242, 652). For further details concerning the methods and basis sets, see ref. 4 and citations therein

16 (a) G. M. Sheldrick, SHELXS-86, University of Göttingen, 1986; (b) G. M. Sheldrick, SHELXL-93, University of Göttingen, 1993. 